\title{
Further studies on the potentiometric salicylate response of polymeric membranes doped with tin(IV)-tetraphenylporphyrins
}

\author{
C.E. Kibbey, S.B. Park, G. DeAdwyler * and M.E. Meyerhoff * \\ Department of Chemistry, The University of Michigan, Ann Arbor, MI 48109 (USA)
}

(Received 25 November 1991; in revised form 9 March 1992)

\begin{abstract}
The chemistry leading to the selective potentiometric response toward salicylate of polymer membranes doped with 5,10,15,20-tetraphenyl(porphyrinato)tin(IV) dichloride ( $\mathrm{Sn}(\mathrm{TPP}) \mathrm{Cl}_{2}$ ) is examined via ${ }^{119} \mathrm{Sn} \mathrm{NMR},{ }^{3} \mathrm{H}_{2} \mathrm{O}$ uptake, spectrophotometric, and solution conductometric techniques. The response properties of ion-selective electrodes prepared with such membranes suggest a complex mechanism of anion binding within the membrane phase. In the pure organic phase, spectroscopic data indicate that salicylate binds directly to one or both axial coordination sites of Sn(IV), displacing the initial chloride ligands. In the presence of water, however, both chloride and salicylate are displaced by water molecules, resulting in a dipositively charged metalloporphyrin cation. Furthermore, conductance measurements point to the formation of salicylate-porphyrin complexes with greater than $2: 1$ stoichiometry. The results of these studies are discussed in conjunction with the anomalous cationic emf response of $\mathrm{Sn}(\mathrm{TPP}) \mathrm{Cl}_{2}$-based membranes at high concentrations of salicylate. A response mechanism is proposed which involves outer-sphere coordination of salicylate to a diaquo ligated metalloporphyrin as a key step in the observed anion extraction/equilibrium with the membrane phase.
\end{abstract}

\section{INTRODUCTION}

Recently, metalloporphyrins have been employed as active membrane components in the design of new liquid/polymeric anion-selective electrodes [1-6]. These metalloporphyrin-based devices display anion selectivities that differ significantly from those of conventional anion-selective electrodes prepared with quater-

\footnotetext{
* Participant in NSF sponsored REU program: present address; Southern Illinois University, Carbondale, IL, USA.

** To whom correspondence should be addressed.
} 
nary ammonium salt ion exchangers [7]. While the exact mechanism of anion response for these electrodes may vary depending on the nature of the porphyrin species doped into the membrane [6], several reports have suggested that the altered anion selectivity patterns are dictated by the relative strength of interaction of anions as axial ligands with the metal center of the metalloporphyrin $[5,7]$ and structural influences from the surrounding porphyrin macrocycle [4].

We have reported previously that plasticized poly(vinyl chloride) membranes doped with 5,10,15,20-tetraphenyl(porphyrinato)tin(IV) dichloride ( $\mathrm{Sn}(\mathrm{TPP}) \mathrm{Cl}_{2}$ ) exhibit selective potentiometric responses toward salicylate over a wide range of other anions, including more lipophilic anions such as thiocyanate and perchlorate [5]. Like other metalloporphyrin-based polymer membrane electrodes, the selectivity of the $\mathrm{Sn}$ (TPP) $\mathrm{Cl}_{2}$ based device was believed to result from the preferred interaction of salicylate with the metalloporphyrin's metal center. Indeed, the decrease in salicylate response for $\mathrm{Sn}(\mathrm{TPP}) \mathrm{Cl}_{2}$-doped polymer membranes prepared with carboxylated poly(vinyl chloride) suggested an associative charge carrier mechanism was operative within the membrane phase [8]. However, the $\mathrm{Sn}$ (TPP) $\mathrm{Cl}_{2}$-based membrane electrode displays several response characteristics toward salicylate (i.e. super-Nernstian response, cationic response at high salicylate concentrations, and unusual response time variations at mid-range concentrations of salicylate [5]), which cannot be explained fully by an associative charge carrier mechanism alone.

The present work provides results from further experiments aimed at probing deeper into the interaction of salicylate with tin(IV) tetraphenylporphyrins. Based on data from ${ }^{119} \mathrm{Sn}$ NMR, visible absorption spectroscopic binding studies, ${ }^{3} \mathrm{H}_{2} \mathrm{O}$ uptake experiments and conductometric titrations, the anomalous salicylate response of the $\mathrm{Sn}$ (TPP)Cl ${ }_{2}$-based electrode is considered in the context of a newly proposed response mechanism that involves an equilibrium outer-sphere interaction of salicylate with a diaquo ligated metalloporphyrin within the organic membrane phase of the ion-selective electrode.

EXPERIMENTAL

\section{Reagents}

Dichloro-(5,10,15,20-tetraphenylporphyrinato)tin(IV) $\left(\mathrm{Sn}(\mathrm{TPP}) \mathrm{Cl}_{2}\right)$ [1] was synthesized from 5,10,15,20-tetraphenyl 21H, 23H-porphine ( $\left.\mathrm{H}_{2} \mathrm{TPP}\right)$ (Aldrich, Milwaukee, WI) and $\mathrm{SnCl}_{2}$ (Aldrich) by the dimethylformamide method [9]. The dinitrate $\left(\mathrm{Sn}(\mathrm{TPP})\left(\mathrm{NO}_{3}\right)_{2}\right)$ and diperchlorate $\left(\mathrm{Sn}(\mathrm{TPP})\left(\mathrm{ClO}_{4}\right)_{2}\right)$ complexes of Sn(TPP) were prepared from the dichloride species by a literature method [10]. The dihydroxide complex $\left(\mathrm{Sn}(\mathrm{TPP})(\mathrm{OH})_{2}\right.$ ) was prepared by refluxing $\mathrm{Sn}(\mathrm{TPP}) \mathrm{Cl}_{2}$ overnight in ammoniacal pyridine [11]. The disalicylate ( $\mathrm{Sn}(\mathrm{TPP}) \mathrm{Sal}_{2}$ ) complex of $\mathrm{Sn}(\mathrm{TPP})$ was prepared from the dichloride $\left(\mathrm{Sn}(\mathrm{TPP}) \mathrm{Cl}_{2}\right.$ ) complex and silver salicylate in dichloromethane. Tetrabutylammonium salicylate (TBA-Sal) was prepared from tetrabutylammonium chloride (TBA-Cl) (Sigma, St. Louis, MO) and sodium salicylate (Aldrich) by a two-phase extraction technique [12]. 
Poly(vinyl chloride) (PVC) (Fluka, Ronkonkoma, NY) and dibutylsebacate (DBS) (Kodak, Rochester, NY) were used to prepare the ion-selective membranes. The tetrahydrofuran (THF) used throughout the experiments was freshly distilled from analytical-reagent grade THF (Mallinckrodt, Paris, KY) over sodium and benzophenone. Dichloromethane (Mallinckrodt, AR grade) was treated with activated basic alumina (Aldrich) and fractionally distilled before use. A $0.05 \mathrm{M}$ 4-morpholinoethanesulfonic acid (MES) (Aldrich) buffer, $\mathrm{pH}$ 5.5, was prepared by dissolving an appropriate amount of MES in a given volume of $16 \mathrm{M} \Omega$ deionized water, and adjusting to $\mathrm{pH} 5.5$ with concentrated $(50 \% \mathrm{w} / \mathrm{w}) \mathrm{NaOH}$ (Mallinckrodt). All other chemicals used in the experiments were analytical-reagent grade.

\section{Preparation of polymer membranes and electrodes}

The PVC-based ISE membranes were prepared as described previously [13], using $1 \mathrm{wt} . \%$ metalloporphyrin, $66 \mathrm{wt} . \%$ DBS, and $33 \mathrm{wt} . \%$ PVC. However, unlike the previously reported membranes, the $\mathrm{Sn}(\mathrm{TPP}) \mathrm{Cl}_{2}$ used here was pretreated with an aqueous buffer before being incorporated into the membrane casting solution (to enhance solubility). This involved preparing a solution of $\mathrm{Sn}(\mathrm{TPP}) \mathrm{Cl}_{2}$ in chloroform $\left(1 \mathrm{mg} \mathrm{ml}^{-1}\right)$, and equilibrating this solution with an equal volume of $50 \mathrm{mM}$ MES buffer, pH 5.5, overnight. Separation of the chloroform layer, followed by solvent evaporation, yielded a metalloporphyrin complex (presumably the diaquo) suitable for incorporation into the PVC membrane. Such pretreatment resulted in a more homogeneous membrane phase than membranes prepared with untreated $\mathrm{Sn}(\mathrm{TPP}) \mathrm{Cl}_{2}$. Working electrodes were prepared by cutting $5.5 \mathrm{~mm}$ diameter disks out of cured membranes and mounting these disks into Philips electrode bodies (ISE-561, Glasblaserei Moller, Zurich). A $0.1 \mathrm{M} \mathrm{KCl}$ solution in deionized water served as the internal filling solution for the working electrodes.

\section{Static mode potentiometric measurements}

The galvanic cell used for all potentiometric measurements was as follows: $\mathrm{Ag} / \mathrm{AgCl}(\mathrm{s}), 4 \mathrm{M} \mathrm{KCl}$ saturated with $\mathrm{AgNO}_{3} / \mathrm{MES}$ buffer/sample solution/ISE membrane $/ 0.1 \mathrm{M} \mathrm{KCl} / \mathrm{AgCl}(\mathrm{s}) / \mathrm{Ag}$. Cell potentials were measured at ambient temperature $\left(22^{\circ} \mathrm{C}\right)$. The $\mathrm{Sn}(\mathrm{TPP})$-based ISE and the $\mathrm{Ag} / \mathrm{AgCl}$ double junction reference electrodes were connected through a high-input impedance amplifier to a Zenith Z-150 computer equipped with a Data Translations DT-2801 analog-todigital converter. A sampling rate of $0.1 \mathrm{~Hz}$ was employed throughout the potentiometric measurements.

\section{Conductance measurements}

The interactions of various anions with $\operatorname{Sn}(\mathrm{TPP})$ in the presence of water were studied using a conductometric method, analogous to that employed by Hughes 
and Tobe to investigate the ligation of anions with $\mathrm{Co}$ (II)-amine complexes [14]. This approach involves determining the conductivity of solutions containing different mole ratios of porphyrin and inorganic salts of the anions, and comparing these measured conductances to theoretical values based on prior calibration data for pure solutions of the metalloporphyrins and inorganic salts. All calibration and measurements were made in unbuffered $60 \% \mathrm{THF}+40 \% \mathrm{H}_{2} \mathrm{O}$ (vol/vol) solutions at $25.0 \pm 0.1^{\circ} \mathrm{C}$. An Orion 018001 conductivity cell (Cambridge, MA) connected to a Yellow Springs Instruments model 35 conductance meter (Yellow Springs, $\mathrm{OH}$ ) was used to determine solution conductances. The conductivity cell had a cell constant of $0.1 \mathrm{~cm}^{-1}$. Conductances were measured after $1 \mathrm{~h}$ of solution equilibration.

\section{Visible spectroscopic measurements}

Visible absorption measurements were performed on a Perkin-Elmer lambda array $3840 \mathrm{UV}-\mathrm{Vis}$ spectrophotometer connected to a Perkin-Elmer model 7300 computer (Perkin-Elmer, Norwalk, CT). Several milliliters of a TBA-Sal solution prepared in dichloromethane were combined with $5 \mathrm{ml}$ of a $1.50 \times 10^{-4} \mathrm{M}$ solution of $\mathrm{Sn}(\mathrm{TPP}) \mathrm{Cl}_{2}$, also prepared in dichloromethane, and enough of the pure solvent to bring the total volume of the solutions to $25 \mathrm{ml}$, yielding solutions spanning a range of 0.30 to 20.88 mole ratio of TBA-Sal to $\mathrm{Sn}(\mathrm{TPP}) \mathrm{Cl}_{2}$. After equilibrating for 3-4 days at room temperature, the absorbance spectra of the solutions were recorded from $500 \mathrm{~nm}$ to $650 \mathrm{~nm}$. The absorbance of the solutions at $601.3 \mathrm{~nm}$ was used for the determination of the two salicylate binding constants. The concentration of unbound salicylate $\left(\mathrm{Sal}_{\mathrm{f}}\right)$ in each solution was calculated from the following equation: $\mathrm{Sal}_{\mathrm{f}}=\mathrm{Sal}_{\mathrm{i}}-(2)\left(F_{\mathrm{c}}\right)\left(c_{\mathrm{t}}\right)$ where, $F_{\mathrm{c}}$ is the fraction of the Sn(TPP) complexed by salicylate, $c_{\mathrm{t}}$ is the total concentration of porphyrin present in solution, and $\mathrm{Sal}_{\mathrm{i}}$ is the initial concentration of TBA-Sal present in solution. The fraction of metalloporphyrin complexed by salicylate $\left(F_{\mathrm{c}}\right)$ was calculated as follows: $F_{\mathrm{c}}=\left(A_{\mathrm{obs}}-A_{\mathrm{u}}\right) /\left(A_{\mathrm{c}}-A_{\mathrm{u}}\right)$ where: $A_{\mathrm{obs}}$ is the absorbance of the sample solutions at $601.3 \mathrm{~nm}$ at equilibrium, $A_{\mathrm{u}}$ is the absorbance of a solution of $\mathrm{Sn}(\mathrm{TPP}) \mathrm{Cl}_{2}$ in the absence of TBA-Sal at $601.3 \mathrm{~nm}$, and $A_{\mathrm{c}}$ is the absorbance of a solution of pure $\operatorname{Sn}(\mathrm{TPP})(\mathrm{Sal})_{2}$ prepared in dichloromethane at $601.3 \mathrm{~nm}$. The concentration of bound salicylate present in the sample solutions at equilibrium was calculated as the difference between the initial concentration of TBA-Sal added and the concentration of free salicylate present at equilibrium: $\mathrm{Sal}_{\mathrm{b}}=\mathrm{Sal}_{\mathrm{i}}$ $-\mathrm{Sal}_{\mathbf{f}}$.

\section{${ }^{119}$ Sn NMR measurements}

${ }^{119}$ Sn NMR spectra were recorded on a Bruker WM-360 instrument at 134 $\mathrm{MHz}$. The acquisition parameters were as follows: spectral width, $931 \mathrm{ppm}$; pulse angle, $45^{\circ}$; acquisition period, $0.131 \mathrm{~s}$; and relaxation delay, $1 \mathrm{~s}$. The ${ }^{119} \mathrm{Sn}$ NMR 
spectra of $\mathrm{Sn}(\mathrm{TPP}) \mathrm{Cl}_{2}$ solutions in $\mathrm{CDCl}_{3}$ containing $0,1,1.5$, and 2.5 mole ratios of TDMA-salicylate were recorded after equilibration of the mixtures overnight.

\section{RESULTS AND DISCUSSION}

Initial potentiometric studies of $\mathrm{Sn}(\mathrm{TPP}) \mathrm{Cl}_{2}$-based polymer membrane electrodes suggested that the high selectivity for salicylate displayed by these sensors is due to the metalloporphyrin serving as an associative charged carrier species within the membrane phase [15]. Such a mechanism would involve direct anion ligand exchange reactions at one or both axial coordination sites of the central Sn(IV) ion. Membrane electrode theory [15] predicts that the resulting potentiometric selectivity pattern should be dependent on the relative stability constants between aqueous sample phase anions and the positively charged carrier sites in the organic membrane phase. Since Sn(IV) is quite oxophilic, it was thought that the porphyrin preferentially coordinates salicylate at one or perhaps both axial sites with a much higher binding constant than other anions (including the original chloride ligands). Indeed, radiotracer uptake studies with $\left[7-{ }^{14} \mathrm{C}\right]$ salicylate (into the PVC membranes) provided indirect evidence to support this hypothesis [5], although the exact stoichiometry of the salicylate-Sn(TPP) reaction, and the strength of salicylate interaction was not assessed during these earlier investigations.

In the present work, ${ }^{119} \mathrm{Sn}$ NMR and visible absorption spectroscopy were used to confirm the direct salicylate binding to the $\mathrm{Sn}(\mathrm{IV})$ center of $\mathrm{Sn}(\mathrm{TPP}) \mathrm{Cl}_{2}$ in an organic phase. As shown in Fig. 1, in the absence of salicylate, a single NMR resonance band is observed for tin, centered at $-587 \mathrm{ppm}$ relative to tetramethyltin (in $\mathrm{CDCl}_{3}$ ). In the presence of a $2.5: 1$ mole excess of salicylate, the band at

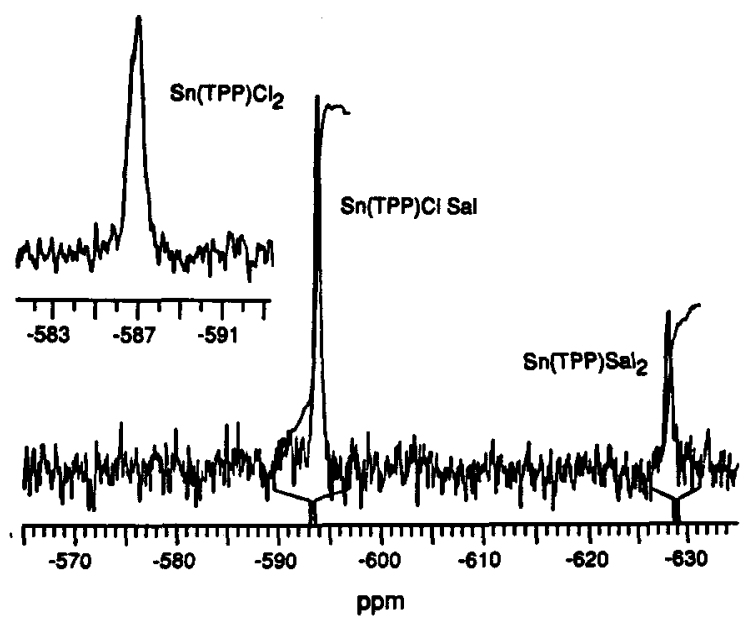

Fig. 1. ${ }^{119} \mathrm{Sn}$ NMR spectra of $\mathrm{Sn}(\mathrm{TPP}) \mathrm{Cl}_{2}$ in $\mathrm{CDCl}_{3}$ alone (inset) and in the presence of TDMA-Sal at a mole ratio of $2.5: 1\left(\mathrm{Sal}: \mathrm{Sn}(\mathrm{TPP}) \mathrm{Cl}_{2}\right)$. 


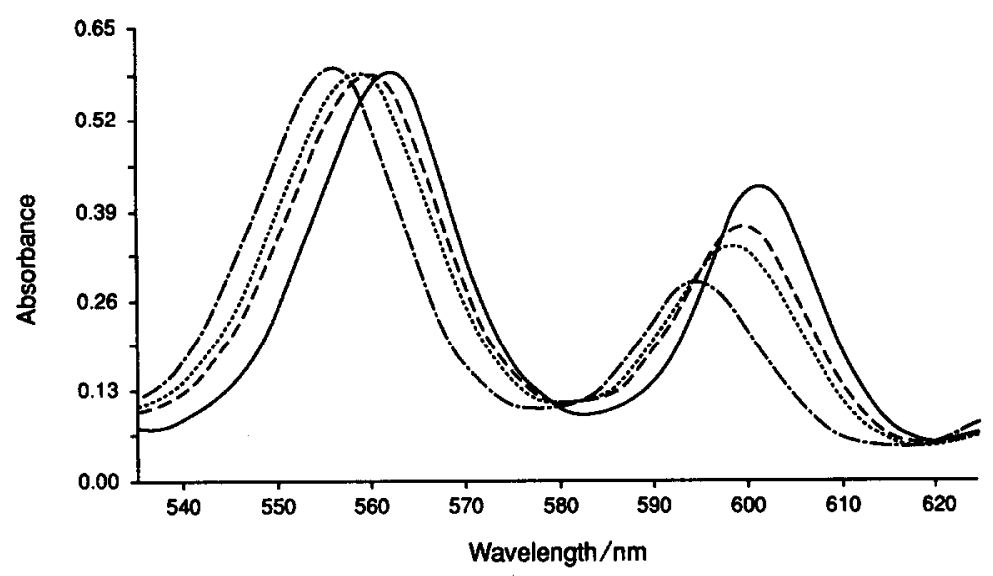

Fig. 2. Visible absorption spectra of $\mathrm{Sn}(\mathrm{TPP}) \mathrm{Cl}_{2}$ in the presence of varying mole ratios of TBA-Sal in dichloromethane: $\mathrm{Sn}(\mathrm{TPP}) \mathrm{Cl}_{2}(-) ; 1 \mathrm{Sn}(\mathrm{TPP}) \mathrm{Cl}_{2}: 1$ TBA-Sal (-- ); $1 \mathrm{Sn}(\mathrm{TPP}) \mathrm{Cl}_{2}: 20$ TBA-Sal $(-\cdot-)$; and $\mathrm{Sn}(\mathrm{TPP})(\mathrm{Sal})_{2}(-\cdot-)$.

$-587 \mathrm{ppm}$ disappears, and two new bands are observed, centered at -594 and $-628 \mathrm{ppm}$. These are assigned to the mono-(Sn(TPP)CISal) and di-salicylate $\left(\mathrm{Sn}(\mathrm{TPP}) \mathrm{Sal}_{2}\right)$ species, respectively. In the presence of higher mole ratios of salicylate to porphyrin, only the resonance for the disalicylate species is observed. These upfield shifts are expected in the light of the increase in electron density around the tin center by the coordinated carboxylate groups of the salicylate. This data confirms that both initial chloride ligands can be readily displaced by salicylate.

The association constants for salicylate coordination with Sn(TPP) can be determined via absorption measurements in the visible region from $500 \mathrm{~nm}$ to 650 $\mathrm{nm}$. The wavelength maxima of the $Q(1,0)$ and $Q(0,0)$ bands of $\operatorname{Sn}(\mathrm{TPP})$ are located within this $150 \mathrm{~nm}$ window. As shown in Fig. 2, the wavelength maxima of the $Q(1,0)$ and $Q(0,0)$ bands of $\operatorname{Sn}(\mathrm{TPP}) \mathrm{Cl}_{2}$ occur at $561.8 \mathrm{~nm}\left(\epsilon=202701 \mathrm{~mol}^{-1}\right.$ $\left.\mathrm{cm}^{-1}\right)$ and $601.3 \mathrm{~nm}\left(\epsilon=141801 \mathrm{~mol}^{-1} \mathrm{~cm}^{-1}\right)$, respectively, in dichloromethane, while those of Sn(TPP)Sal ${ }_{2}$ occur at $555.5 \mathrm{~nm}\left(\epsilon=20667 \mathrm{I} \mathrm{mol}^{-1} \mathrm{~cm}^{-1}\right)$ and $594.2 \mathrm{~nm}\left(\epsilon=9048 \mathrm{I} \mathrm{mol}^{-1} \mathrm{~cm}^{-1}\right)$, respectively, in the same solvent. Replacing the chloride ligands of $\mathrm{Sn}(\mathrm{TPP}) \mathrm{Cl}_{2}$ with salicylate results in a blue-shift of the $Q(1,0)$ and $Q(0,0)$ bands, as well as a decrease in molar absorptivity of the $Q(0,0)$ bands. The blue shift of the $\mathrm{Sn}$ (TPP)Cl $\mathrm{Cl}_{2}$ absorption bands, coupled with the decrease in absorptivity of the $Q(0,0)$ band that occurs, as the amount of TBA-Sal in solution is increased (Fig. 2), is consistent with axial ligand exchange of chloride for salicylate on $\mathrm{Sn}$ (TPP).

The visible absorbance data (Fig. 2) were used to determine the two equilibrium binding constants for salicylate ligation to $\mathrm{Sn}$ (TPP) in dichloromethane (see Experimental). The calculations are based upon the assumption that the molar absorptivity of the $Q(0,0)$ band of $\operatorname{Sn}(\mathrm{TPP})$ changes by an equivalent amount as 


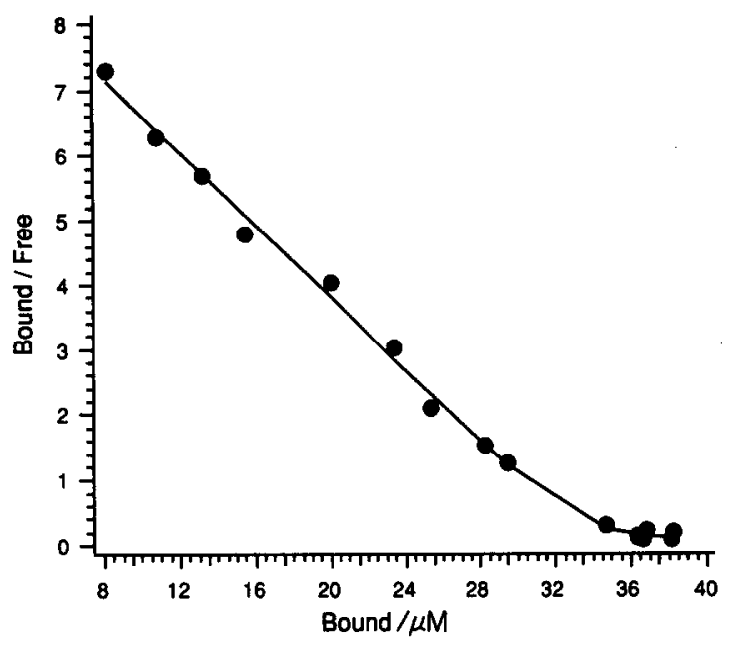

Fig. 3. Scatchard plot for the interaction of salicylate with $\left.3 \times 10^{-5} \mathrm{M} \mathrm{Sn} \mathrm{TPP}\right) \mathrm{Cl}_{2}$ in dichloromethane as measured by visible absorption spectroscopy.

axial coordination to the metalloporphyrin proceeds from $\mathrm{Sn}(\mathrm{TPP}) \mathrm{Cl}_{2}$ through $\mathrm{Sn}(\mathrm{TPP})(\mathrm{Cl})(\mathrm{Sal})$ to $\mathrm{Sn}(\mathrm{TPP})(\mathrm{Sal})_{2}$. Data for this experiment are plotted in Scatchard form [16] in Fig. 3. Analysis of this data by a least-squares curve fit to the Scatchard equation describing coordination of one ligand to two binding sites yielded binding constants of $K_{\mathrm{al}}=(2.84 \pm 0.08) \times 10^{5} \mathrm{M}^{-1}$ and $K_{\mathrm{a} 2}=75 \pm 211$ $\mathrm{M}^{-1}$ for the following reactions:

$$
\begin{aligned}
& \mathrm{Sn}(\mathrm{TPP}) \mathrm{Cl}_{2}+\mathrm{Sal}^{-} \stackrel{K_{\mathrm{al}}}{\rightleftarrows} \mathrm{Sn}(\mathrm{TPP})(\mathrm{Cl})(\mathrm{Sal}) \\
& \mathrm{Sn}(\mathrm{TPP})(\mathrm{Cl})(\mathrm{Sal})+\mathrm{Sal}^{-} \stackrel{K_{\mathrm{a} 2}}{\rightleftarrows} \mathrm{Sn}(\mathrm{TPP})(\mathrm{Sal})_{2}
\end{aligned}
$$

The large standard deviation in the value of $K_{\mathrm{a} 2}$ reflects the fact that little of the disalicylate complex was formed in dichloromethane solutions containing up to a twentyfold molar excess of TBA-Sal. It should be noted that the $\mathrm{pH}$ response [5] of the Sn(TPP)-based membrane electrode suggests that water is potentially a very strong ligand (also see below). Therefore, in order to simplify the study of direct salicylate ligation to the Sn(IV) center, aquation of the metalloporphyrin was prevented through the use of anhydrous dichloromethane. In addition, the equilibrium constants reported do not take into account the liberated chloride ions from the original $\mathrm{Sn}$ (TPP) $\mathrm{Cl}_{2}$; hence these association constants only reflect the displacement of chloride by salicylate on Sn(TPP) and cannot be interpreted as being formal ion exchange constants. While the ${ }^{119} \mathrm{Sn} \mathrm{NMR}$ data indicates the formation of an appreciable amount of $\mathrm{Sn}(\mathrm{TPP})(\mathrm{Sal})_{2}$ at a mole ratio of $2.5 \mathrm{Sal}: 1 \mathrm{Sn}(\mathrm{TPP}) \mathrm{Cl}_{2}$ in $\mathrm{CDCl}_{3}$, the results of visible absorption spectroscopy suggest little of the disalicylate complex is formed at the same mole ratio in dichloromethane. This apparent discrepancy may be due to the use of different solvents in the two 
experiments. Nonetheless, the relatively large binding constant for the first ligand association may help explain the slow recovery times when the Sn(TPP)-based salicylate electrode is switched from a solution containing high concentrations of salicylate to one that contains low levels. Indeed, while the kinetics of the salicylate ligation reaction have not yet been studied, sluggish response and recovery times of the metalloporphyrin-based sensor, particularly at high sample salicylate concentrations (e.g. $1 \mathrm{mM}$ ), suggest slow forward and reverse rate constants for reaction (1) above, or analogous reactions involving diaquo Sn(TPP) species (see below). The long equilibration times (3-4 days) needed in the study of reactions (1) and (2) above in anhydrous dichloromethane indicate a slow kinetic rate for axial ligand exchange on Sn(TPP).

Although the results of ${ }^{119} \mathrm{Sn}$ NMR and visible absorption spectroscopy demonstrate strong axial coordination of salicylate to the tin center of $\mathrm{Sn}(\mathrm{TPP}) \mathrm{Cl}_{2}$, the metalloporphyrin-based electrode's overall response to anions, such as salicylate, cannot be interpreted solely by the simple picture of ion-exchange that emerges from the above NMR and visible absorption spectroscopy experiments. The fact that the Sn(TPP)-based electrodes often exhibit super-Nernstian slopes toward salicylate (up to $80 \mathrm{mV}$ decade ${ }^{-1}$ when greater than $1 \mathrm{wt} . \%$ porphyrin is doped into the membrane) and have response times that vary in an unusual way with analyte concentration (see Fig. 2 in ref. 5) suggests that a more complex chemistry of salicylate interaction is involved. Also unusual is the e.m.f. response of the sensor at high concentrations of salicylate. As shown in Fig. 4, at concentrations greater than $5 \mathrm{mM}$, the response of the electrode actually reverses and becomes what appears to be cationic. For comparison purposes, dynamic response data are

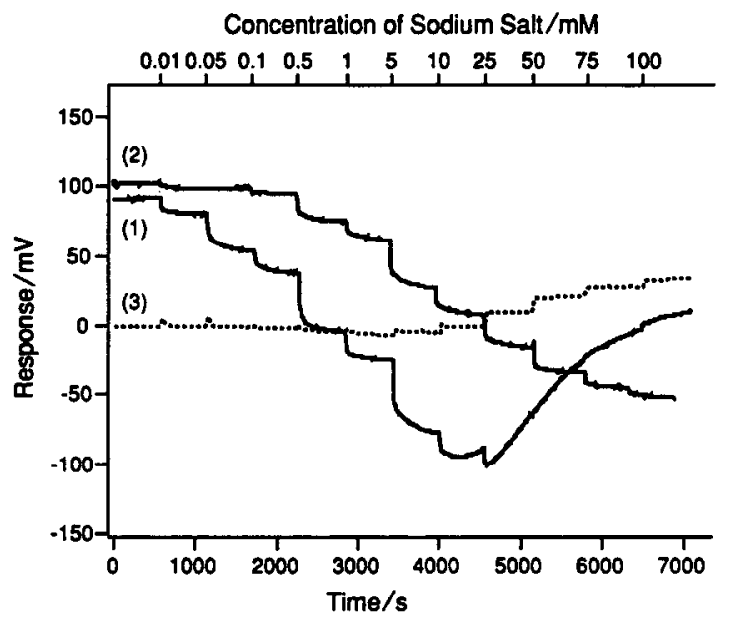

Fig. 4. Potentiometric response of polymer membrane ISE containing $1 \mathrm{wt} \% \mathrm{Sn}(\mathrm{TPP})$ to sodium salicylate (1) and sodium thiocyanate (2), and the response of a blank PVC membrane to sodium salicylate (3) in a $50 \mathrm{mM}$ MES buffer, pH 5.5 . 
also shown for the Sn(TPP)-based electrode's response to thiocyanate, as well as for a blank PVC membrane electrode (without metalloporphyrin) towards sodium salicylate. While the blank PVC membrane does show slight cation response, the positive drift in response of the Sn(TPP)-based electrode to high levels of salicylate is almost three times greater than the response of the blank membrane. Such reversal in electrode e.m.f. response is not predicted for carriers that function via an associated charged carrier mechanism [15].

The cationic response of the Sn(TPP)-based ISE at higher salicylate concentrations is, however, quite similar to the behavior of neutral carrier-based cation selective electrodes in the absence of additional lipophilic counter anions within the membrane phase [15]. In such instances, complexation of cations by the neutral carrier at higher sample cation concentrations results in the formation of excess positively charged carrier species in the membrane, and this induces a change in the electrode's response from cationic to anionic (i.e. Donnan failure). The magnitude of the anionic interference suffered by a cation-selective neutral carrier-based electrode is governed by the lipophilicity of the counter anion present in the aqueous sample solution. Perchlorate and thiocyanate produce large deviations from normal cation response, while the presence of chloride causes little interference.

The Sn(TPP)-based membrane electrode's reversal in response in the presence of high salicylate concentrations may result from a response to cations in the sample in a manner analogous to the anion response observed with neutral carrier-based cation electrodes. That is, anion interactions with the porphyrin may cause the establishment of a negatively charged complex in the membrane phase, which would then induce the partitioning of cations into the polymer membrane and would yield a positive potentiometric response. In theory a more lipophilic cation would be expected to yield a greater cation response due to its greater partition into the membrane phase [15]. However, when experiments such as those depicted in Fig. 4 were carried out using both rubidium and sodium salts of salicylate (to prepare standards), very little difference in the magnitude of the cationic drift at high salicylate concentrations was observed (data not shown). (Note: Gibbs energies of hydration for $\mathrm{Rb}^{+}$and $\mathrm{Na}^{+}$are -314 and $-410 \mathrm{~kJ}$ mol $^{-1}$ respectively.)

Since, in practice, a significant amount of water is present within the membrane phase of operative Sn(TPP)-based electrodes, the strong coordination of water to the axial sites of $\operatorname{Sn}(\mathrm{IV})$ may influence greatly the interactions of the Sn(TPP) species with anions. Evidence for water coordination was obtained by radiotracer experiments involving ${ }^{3} \mathrm{H}_{2} \mathrm{O}$. Results for the radiotracer uptake experiments arc shown in Fig. 5. Clearly, the rate of water uptake by the polymer membrane is enhanced greatly, relative to blank membranes (i.e. no porphyrin added), when the $\operatorname{tin}(\mathrm{IV})$-porphyrin is present. In addition, when a $\mathrm{Sn}(\mathrm{TPP}) \mathrm{Cl}_{2}$ solution in toluene or chloroform is equilibrated with water, the infrared absorption spectrum of the recovered porphyrin clearly shows a Sn- $\mathrm{OH}_{2}$ absorption band at $560 \mathrm{~cm}^{-1}$ (data not shown). Therefore, to gain further insight into the reactions of salicylate and 


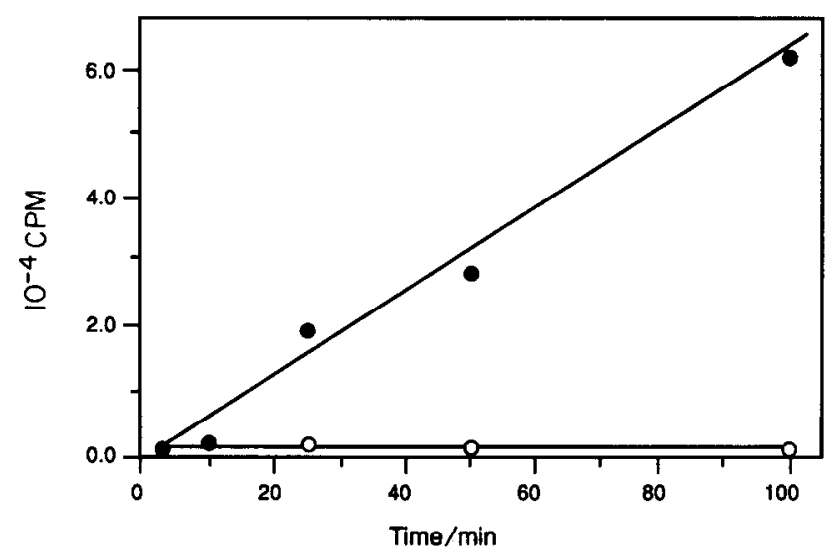

Fig. 5. Rate of ${ }^{3} \mathrm{H}_{2} \mathrm{O}$ uptake by a blank PVC membrane (O) and a membrane containing 1 wt.\% Sn(TPP) (•). (See ref. 5 for experimental details regarding quantitating radioactivity in polymer membrane phase.)

other anions with Sn(TPP) in the presence of water, conductometric studies were undertaken. The conductometric method offers an advantage over spectroscopic techniques in the study of metalloporphyrin-ligand interactions by providing a generic means of detecting the relative number of free ions in solution. Indeed, the solvent mediated dissociation of several chloride ligated metalloporphyrins has been studied previously by conductivity [17].

The lipophilicity of the $\mathrm{Sn}(\mathrm{TPP}) \mathrm{Cl}_{2}$ requires that the conductance measurements be carried out in an aqueous + organic solvent mixture. The choice of organic solvent is limited to those that are miscible with water and do not coordinate to the tin center of the metalloporphyrin. A number of organic solvents were screened to determine their coordination properties with $\mathrm{Sn}(\mathrm{TPP}) \mathrm{Cl}_{2}$ via UV-Vis absorbance measurements [17,18]. Of those examined, THF was chosen as the most compatible organic solvent for the conductance studies, and all subsequent conductance measurements were made in a $60 / 40 \mathrm{vol} / \mathrm{vol}$ mixture of $\mathrm{THF}+\mathrm{H}_{2} \mathrm{O}$ in which all the metalloporphyrins were soluble.

The conductance of solutions of tin(IV) tetraphenylporphyrins and sodium salts of chloride, thiocyanate, salicylate, benzoate, and para-hydroxybenzoate were measured separately in order to obtain independent calibration data for each species (i.e. effectively the specific conductances of these compounds). A plot of the solution conductance versus concentration is shown in Fig. 6 for several tin(IV) metalloporhyrins and sodium chloride. The high slopes of the $\operatorname{Sn}(\mathrm{TPP}) \mathrm{Cl}_{2}$, $\mathrm{Sn}(\mathrm{TPP})\left(\mathrm{NO}_{3}\right)_{2}$, and $\mathrm{Sn}(\mathrm{TPP})\left(\mathrm{ClO}_{4}\right)_{2}$ calibration curves, compared to that of $\mathrm{NaCl}$, indicate that the metalloporphyrins dissociate in the THF $+\mathrm{H}_{2} \mathrm{O}$ solution to a greater extent than the $1: 1$ salt $\mathrm{NaCl}$. The $\mathrm{Sn}(\mathrm{TPP}) \mathrm{Cl}_{2}$ calibration slope is slightly lower than those of either the dinitrate or diperchlorate, which indicates that the latter are dissociated more completely than the dichloride species. 


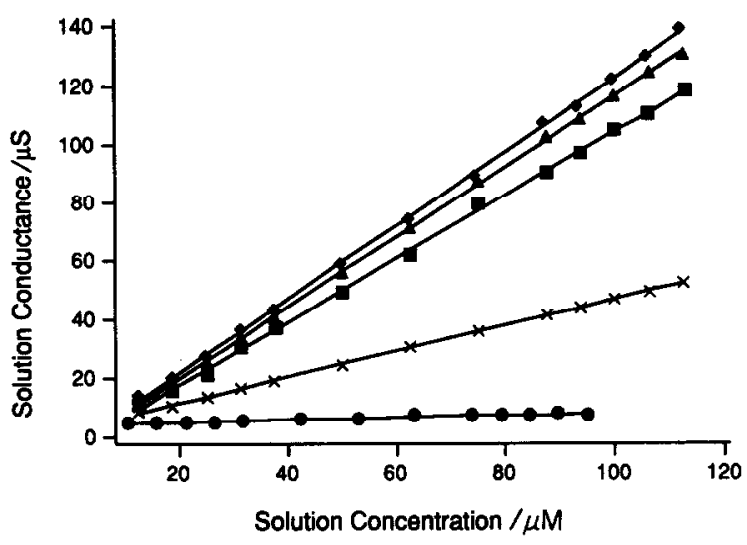

Fig. 6. Conductance calibration curves in $60 \% \mathrm{THF}+40 \% \mathrm{H}_{2} \mathrm{O}$ for $\mathrm{Sn}(\mathrm{TPP}) \mathrm{Cl}_{2}(\square), \mathrm{Sn}(\mathrm{TPP})\left(\mathrm{ClO}_{4}\right)_{2}$ $(\triangleleft), \mathrm{Sn}(\mathrm{TPP})\left(\mathrm{NO}_{3}\right)_{2}(\bullet), \mathrm{Sn}(\mathrm{TPP})(\mathrm{OH})_{2}(\bullet)$, and $\mathrm{NaCl}(\times)$.

Presumably, water molecules displace the initial axial anion ligands of these various Sn(TPP) structures, and this corroborates previous IR, and radiotracer observations regarding the ligation of water. Similarly, Inoue et al. have suggested that a shift in the Soret band of $\mathrm{Sn}(\mathrm{TPP}) \mathrm{Cl}_{2}$ upon the addition of water to an acetonitrile solution of the metalloporphyrin is caused by the spontaneous displacement of chloride ligands by water [19]. The favorable coordination of water to $\mathrm{Sn}$ (TPP) $\mathrm{Cl}_{2}$, and the appreciable conductance of the metalloporphyrin solutions indicates that $\mathrm{Sn}(\mathrm{TPP})\left(\mathrm{H}_{2} \mathrm{O}\right)_{2}^{2+}$ is the divalent species present in the THF $+\mathrm{H}_{2} \mathrm{O}$ solutions. Interestingly, $\mathrm{Sn}(\mathrm{TPP})(\mathrm{OH})_{2}$ exhibits little dissociation in $60 \% \mathrm{THF}+$ $40 \% \mathrm{H}_{2} \mathrm{O}$ (as indicated by its extremely low slope in the calibration plot (see Fig. 6)). This suggests that hydroxide ions are bound tightly as axial ligands and supports the notion that the $\mathrm{pH}$ response of Sn(TPP)-based membranes may result from a protonation/deprotonation equilibrium involving strongly ligated water/hydroxide [5].

The tin(IV) tetraphenylporphyrin and sodium salt solutions were combined following a continuous variation approach [20] to yield solutions with different porphyrin/anion ratios. The conductances of these mixed solutions were measured immediately after preparation and at $1 \mathrm{~h}$ intervals thereafter. If the species present in solution obey Kohlrausch's law of independent migration of ions [21], then the conductance of the combined solutions should equal the sum of the conductances of the solutions measured separately (i.e. prior calibration data). Ilowever, any interactions between ions in solution (e.g., ion-pair formation, or complexation) should result in a measured solution conductance that is less than the sum of the contributions to the total solution conductance from the individual ions. To avoid problems due to changes in ionic strength (i.e. effect on activity coefficients for each ion), all measurements were made in relatively dilute solutions of the porphyrins and anions $(0.01-0.1 \mathrm{mM})$. The conductance data was treated by 


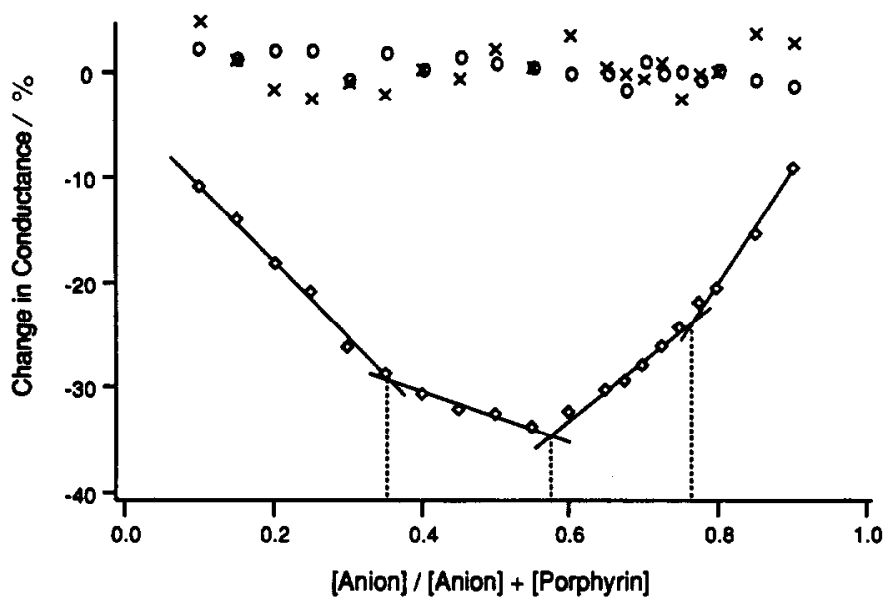

Fig. 7. Plots of $\%$ change in solution conductance versus solution composition for mixtures of $\mathrm{Sn}(\mathrm{TPP}) \mathrm{Cl}_{2}$ with sodium salicylate $(\diamond)$, sodium thiocyanate $(x)$ and sodium chloride $(0)$.

calculating the percentage change in conductance relative to the predicted solution conductance (as determined from the separate calibration data).

The results of these conductometric studies for the interaction of thiocyanate and salicylate with $\mathrm{Sn}(\mathrm{TPP}) \mathrm{Cl}_{2}$, and for the interaction of chloride with $\mathrm{Sn}(\mathrm{TPP})\left(\mathrm{NO}_{3}\right)_{2}$ are shown in Fig. 7. It is clear that little or no change in the measured conductances are observed for thiocyanate and chloride, indicating that these species do not bind to the metalloporphyrin to any significant degree. However, rather large deviations from theoretical conductances are observed when salicylate is present. This interaction is independent of the axial ligands initially present on the porphyrin (i.e. the same type of curves for dichloride, dinitrate, and diperchlorate Sn(TPP) species are observed; data not shown here). The initial anionic ligand does not influence the metalloporphyrin's interactions with salicylate, because such interactions appear to occur through the $\operatorname{Sn}(\mathrm{TPP})\left(\mathrm{H}_{2} \mathrm{O}\right)_{2}^{2+}$ species that predominates in solution, and not the neutral anion-ligated complex.

The results of the conductance experiments shown in Fig. 7 correlate with the potentiometric anion selectivity pattern reported previously for $\mathrm{Sn}(\mathrm{TPP}) \mathrm{Cl}_{2}$-doped polymer membranes. Anions such as chloride and thiocyanate, to which the Sn(TPP)-based electrode exhibits relatively little response (i.e. $\log k_{\mathrm{Sal}^{\mathrm{O}} \mathrm{C}^{-}}^{\text {pot }}=-3.8$; $\log k_{\mathrm{Sal}^{\mathrm{S}} \mathrm{SCN}}^{\text {pot }}=-2.5$ ), display little interaction with the metalloporphyrin in THF + $\mathrm{H}_{2} \mathrm{O}$ solution. Salicylate, for which the $\mathrm{Sn}(\mathrm{TPP}) \mathrm{Cl}_{2}$-based membrane electrodes exhibit high selectivity, interacts strongly with the metalloporphyrin in solution.

Portions of the conductance plots for salicylate/Sn(TPP) interactions shown in Fig. 7 were linearized by a least-squares fit, and adjacent line segments intersected, in order to determine the stoichiometries of prominent species present in solution. Three distinct species are observed for interaction of salicylate with the metalloporphyrin. The stoichiometries of the three species correspond to 1 salicylate: 2 
metalloporphyrins; 1 salicylate:1 metalloporphyrin; and 3 salicylates: 1 metalloporphyrin. Given that tin(IV) tetraphenylporphyrin has two axial sites available for ligation, one would expect a maximum stoichiometry of 2 carboxylates: 1 metalloporphyrin. The fact that the conductance data indicates the presence of a $3: 1$ ligand:metalloporphyrin species suggests that the interaction of the aromatic carboxylates with $\mathrm{Sn}(\mathrm{TPP}) \mathrm{Cl}_{2}$ does not necessarily involve a direct axial ligation of the anions to the tin center of $\operatorname{Sn}(\mathrm{TPP})$ in the presence of water. Indeed, both the $Q(1,0)$ and the $Q(0,0)$ bands of $\operatorname{Sn}(\mathrm{TPP})(\mathrm{Sal})_{2}$ prepared in dry THF are shifted from $555.5 \mathrm{~nm}$ and $594.2 \mathrm{~nm}$, respectively, to $557.5 \mathrm{~nm}$ and $597.0 \mathrm{~nm}$ when the disalicylate form of the metalloporphyrin is prepared in a $60 \% \mathrm{THF}+40 \% \mathrm{H}_{2} \mathrm{O}$ solution. This red shift of the $Q(1,0)$ and $Q(0,0)$ bands of $\operatorname{Sn}(\mathrm{TPP})(\mathrm{Sal})_{2}$ in the presence of water indicates that water ligates more strongly to the $\mathrm{Sn}(\mathrm{IV})$ center of the metalloporphyrin than does salicylate.

Based on the above data it is possible that salicylate (and other aromatic carboxylates that the Sn(TPP)-based electrode responds to, e.g. benzoate) are held in an outer-coordination sphere through hydrogen bonding interactions with the protons of the water molecules of $\operatorname{Sn}(\mathrm{TPP})\left(\mathrm{H}_{2} \mathrm{O}\right)_{2}^{2+}$. The lack of a shift in the visible absorption bands of tin(IV) tetraphenylporphyrin dichloride in $60 \% \mathrm{THF}+$ $40 \% \mathrm{H}_{2} \mathrm{O}$ in the presence of a fivefold excess of salicylate corroborates outer-sphere rather than inner-sphere coordination. Furthermore, the conductance data taken immediately after the solutions were prepared, and measurements made $5 \mathrm{~h}$ later, consistently point to a 3:1 rather than a $2: 1$ ligand:metalloporphyrin stoichiometry, suggesting that the outer-sphere coordination of the carboxylates is quite stable in the $60 \% \mathrm{THF}+40 \% \mathrm{H}_{2} \mathrm{O}$ solvent.

The results of the solution conductance measurements and potentiometric behavior of Sn(TPP)-based membrane electrodes to salicylate point to a process that proceeds via anation of the diaquo ligated metalloporphyrin in an ion-pair interchange mechanism similar to that considered for the anation of cobalt(III) metalloporphyrins by thiocyanate [22,23]. A possible mechanism for salicylate ligand exchange with $\mathrm{Sn}(\mathrm{TPP}) \mathrm{Cl}_{2}$ in the polymer membranc phase is depicted in Fig. 8. The first step of the ligand exchange process involves aquation of the dichloride ligated metalloporphyrin. All existing spectroscopic, ${ }^{3} \mathrm{H}_{2} \mathrm{O}$ membrane uptake, and potentiometric $\mathrm{pH}$ response data indicate that very rapid aquation of $\mathrm{Sn}$ (TPP) $\mathrm{Cl}_{2}$ occurs in the membrane phase of these electrodes. The formation of a pre-equilibrium outer-sphere complex of salicylate with the $\operatorname{Sn}(\mathrm{TPP})\left(\mathrm{H}_{2} \mathrm{O}\right)_{2}^{2+}$ with a maximum stoichiometry (presumably) of 3:1 (respectively) comprises the second step of the response mechanism. While the existence of such an outer-sphere complex has not been verified by more direct means, or detected in the polymer membrane phase of the electrodes, the presence of the complex in $60 \% \mathrm{THF}+40 \%$ $\mathrm{H}_{2} \mathrm{O}$ solution appears to be substantiated by the conductometric experiments. This outer-sphere interaction of salicylate probably predominates at low to moderate sample concentrations of salicylate. The third step of the salicylate response mechanism involves the exchange of outer-sphere coordinated salicylate for innersphere water ligands. This occurs when the sample salicylate concentration is high 

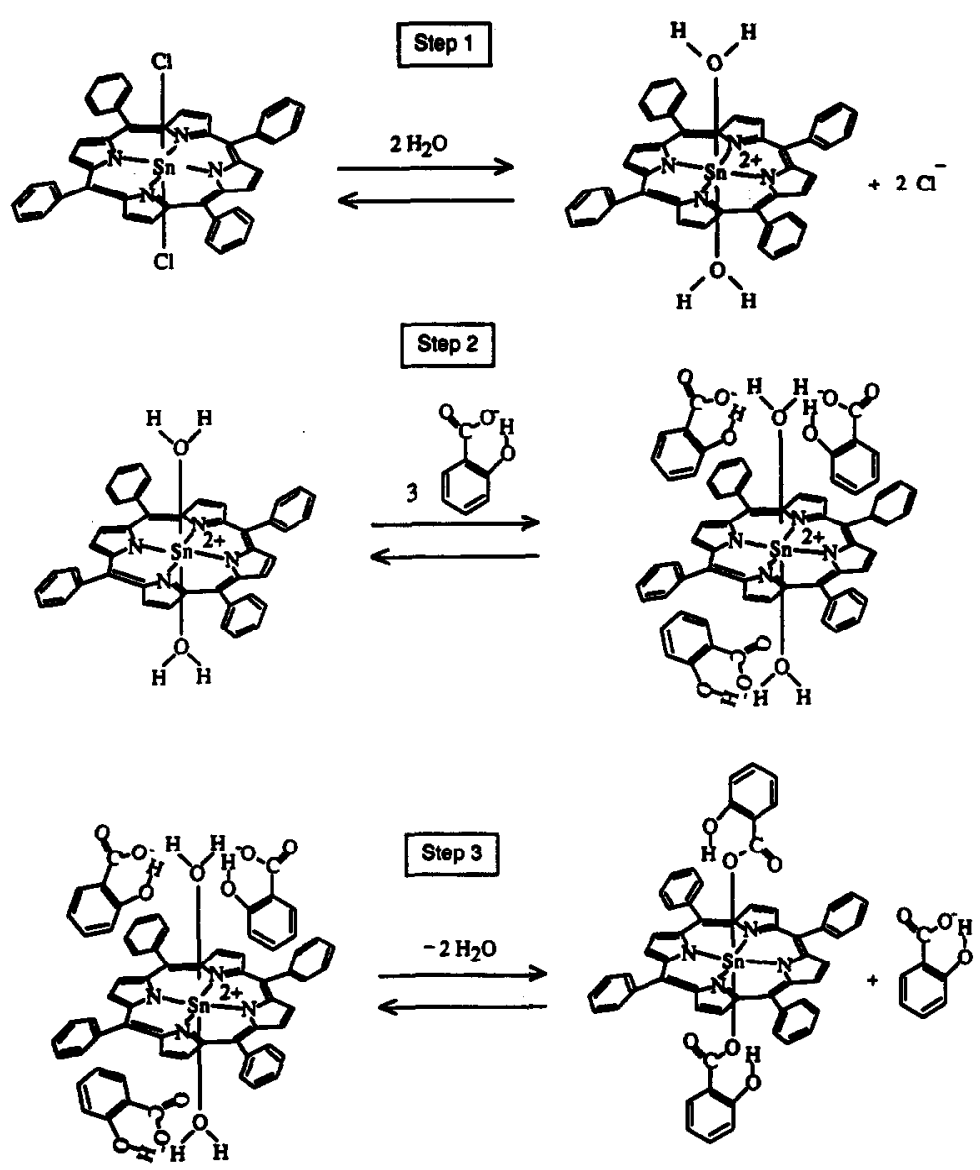

Fig. 8. Proposed 3-step mechanism for interactions of salicylate with Sn(TPP) in the membrane phase of porphyrin-based ISE.

enough to effectively compete with water for one or both inner-sphere coordination sites. This results in the formation of the neutral $\operatorname{Sn}(\mathrm{TPP})(\mathrm{Sal})_{2}$ species or $\mathrm{Sn}(\mathrm{TPP})(\mathrm{Sal})\left(\mathrm{H}_{2} \mathrm{O}\right)^{+}(\mathrm{Sal})^{-}$in the membrane phase along with a third salicylate anion. Partition of this third non-coordinated salicylate out of the membrane phase would explain the apparent cationic potentiometric response of the $\mathrm{Sn}(\mathrm{TPP}) \mathrm{Cl}_{2}-$ based polymer membrane electrode in the presence of $>5 \mathrm{mM}$ salicylate (Fig. 5).

In summary, the data presented here indicate that the response mechanism of salicylate selective electrodes based on $\mathrm{Sn}(\mathrm{TPP}) \mathrm{Cl}_{2}$ is more complex than first believed. While salicylate can in fact bind at both axial ligand coordination sites of $\mathrm{Sn}(\mathrm{IV})$, water is also a very strong ligand that can compete for these inner-sphere sites. Indeed, it appears that salicylate complexation via hydrogen bonding and perhaps some $\pi-\pi$ interactions with the diaquo porphyrin species ( $\operatorname{Sn}(\mathrm{TPP})$ - 
$\left.\left(\mathrm{H}_{2} \mathrm{O}\right)_{2}^{+}\right)$is responsible for the initial extraction of salicylate into the polymeric membrane. At higher concentrations of sample salicylate, a combination of salicylate interactions as both an outer- and inner-sphere ligand (displacing the water) probably occurs. Clearly, additional fundamental studies to further confirm this response mechanism for the $\mathrm{Sn}$ (TPP)-based electrodes are warranted, as are similar efforts to explain the unusual response properties of membrane electrodes prepared with other metalloporphyrins (e.g., $\operatorname{In}(\mathrm{TPP}) \mathrm{Cl}$ [24]).

\section{ACKNOWLEDGMENTS}

The authors gratefully acknowledge financial support for this work from the National Institutes for Health (GM 28882-10). G.D. wishes to thank the National Science Foundation for supporting her undergraduate research experience via an NSF-REU grant to the Department of Chemistry at the University of Michigan. C.K. acknowledges financial support from Bacharach Inc. via an American Chemical Society graduate student summer fellowship.

\section{REFERENCES}

1 D. Ammann, M. Hoser, B. Kräutler, B. Rusterholz, P. Schulthess, B. Lindermann, E. Hadler and W. Simon, Helv. Chim. Acta, 69 (1986) 849.

2 A. Hodinár and A. Jyo, Chem. Lett., 6 (1988) 993.

3 D.V. Brown; N.A. Chaniotakis, I.H. Lee, S.C. Ma, S.B. Park, R.J. Nick, J.T. Groves and M.E. Meyerhoff, Electroanalysis, 1 (1989) 477.

4 N.A. Chaniotakis, A.M. Chasser and M.E. Meyerhoff, Anal. Chem., 60 (1988) 188.

5 N.A. Chaniotakis, S.B. Park and M.E. Meyerhoff, Anal. Chem., 61 (1989) 566.

6 M.E. Meyerhoff, Proc. 176th Meeting of the Electrochemical Society, paper 689.

7 Q. Chang, S.B. Park, D. Kliza, G.S. Cha, H. Yim and M.E. Meyerhoff, Am. Biotechnol. Lab., 8(1) (1990) 10.

8 S.C. Ma, N.A. Chaniotakis and M.E. Meyerhoff, Anal. Chem., 60 (1988) 2293.

9 J.W.S. Buchler, in D. Dolphin (Ed.), The Porphyrins, Vol. 1, Part A, Academic Press, New York, 1978, p. 408.

10 D.P. Arnold, Polyhedron, 5(12) (1986) 1957.

11 G. Meyer, M. Hartmann and D. Wöhrle, Makromol. Chem., 176 (1975) 1919.

12 M.E. Meyerhoff, E. Pretsch, D.H. Welti and W. Simon, Anal. Chem., 59(1) (1987) 144.

13 U. Wuthier, H.V. Pham, R. Zund, D. Welti, R.J.J. Funk, A. Bezegh, D. Ammann E. Pretsch and W. Simon, Anal. Chem., 56 (1984) 535.

14 M.N. Hughes and M.L. Tobe, J. Chem. Soc., Part 1 (1965) 1204.

15 W.E. Morf, The Principles of Ion-Selective Electrodes and of Membrane Transport, Elsevier, New York, 1981, Chapters 11 and 12.

16 H.A. Feldman, Anal. Biochem., 48 (1972) 317.

17 M. Hoshino, S. Katayama and K. Yamamoto, Bull. Chem. Soc. Jpn., 58 (1985) 3360.

18 J.R. Miller and G.D. Dorough, J. Am. Chem. Soc., 74 (1952) 3977.

19 H. Inoue, K. Chandrasekaran and D. Whitten, J. Photochem., 30 (1985) 269.

20 H.H. Willard, L.L. Merritt, J.A. Dean and F.A. Settle, Instrumental Methods of Analysis, 6th edn., Van Nostrand, New York, 1981, p. 942.

21 P.W. Atkins, Physical Chemistry, 3rd edn., W.H. Freeman, New York, 1986, p. 666.

22 E.B. Fleischer, S. Jacobs and L. Mestichelli, J. Am. Chem. Soc., 90 (10) (1968) 2527.

23 K.R. Ashley, M. Berggren and M. Cheng, J. Am. Chem. Soc., 97(6) (1975) 1422.

24 S.B. Park, W. Matuszewski , M.E. Meyerhoff, Y.H. Lui and K.M. Kadish, Electroanalysis, 3 (1991) 909. 